\title{
Foetal origins of depression? A systematic review and meta-analysis of low birth weight and later depression
}

\author{
W. Wojcik $^{1 *}$, W. Lee ${ }^{1}$, I. Colman ${ }^{2}$, R. Hardy ${ }^{3}$ and M. Hotopf ${ }^{1}$ \\ ${ }^{1}$ Department of Psychological Medicine, Institute of Psychiatry, King's College London, UK \\ ${ }^{2}$ Department of Epidemiology and Community Medicine, University of Ottawa, ON, Canada \\ ${ }^{3}$ MRC Unit for Lifelong Health and Ageing, University College London, UK
}

Background. The foetal origins hypothesis suggests an association between low birth weight and later depression, yet evidence supporting this association has been inconsistent.

\begin{abstract}
Method. We systematically reviewed evidence for an association between low birth weight and adult depression or psychological distress in the general population by meta-analysis. We searched EMBASE, Medline, PsycINFO and ISI Web of Science for studies reporting observational data with low birth weight as the exposure and self- or clinicianrated depression or psychological distress measures as an outcome. Selective studies of exposures such as famine or outcomes such as severe illness only were excluded. Altogether,1454 studies were screened for relevance, 26 were included in the qualitative synthesis, 18 were included in the meta-analysis. A random effects meta-analysis method was used to obtain a pooled estimate of effect size.
\end{abstract}

Results. The odds of depression or psychological distress was greater for those of low birth weight $(<2500 \mathrm{~g})$ compared to those of normal birth weight $(>2500 \mathrm{~g}$ ) or greater [odds ratio (OR) $1.15,95 \%$ confidence intervals $(\mathrm{CI})$ 1.00-1.32]. However, this association became non-significant after trim-and-fill correction for publication bias (OR $1.08,95 \%$ CI $0.92-1.27)$. Using meta-regression, no differences in effect size were observed by gender, outcome measure of depression or psychological distress, or whether the effect size was adjusted for possible confounders.

Conclusions. We found evidence to support a weak association between low birth weight and later depression or psychological distress, which may be due to publication bias. It remains possible that the association may vary according to severity of symptoms or other factors.

Received 14 June 2011; Revised 6 March 2012; Accepted 8 March 2012 ; First published online 13 April 2012

Key words: Birth weight, depression, fetal origins, psychological distress.

\section{Introduction}

Over the past two decades a growing body of research has linked low birth weight to a variety of adult health outcomes, first and most compellingly for cardiovascular disease (Barker et al. 1989; Barker, 2004; Huxley et al. 2007), but also for hypertension and type II diabetes (Barker et al. 2006; Whincup et al. 2008) and less clearly some mental disorders (Jones et al. 1998; Breslau \& Chilcoat, 2000). These findings support what is variously termed the 'Barker hypothesis', 'foetal origins hypothesis' or 'developmental origins of adult health and disease hypothesis' (Barker, 2007). It describes developmental plasticity in the foetus and

* Address for correspondence: Dr W. Wojcik, Department of Psychological Medicine, Weston Education Centre, Institute of Psychiatry, London SE5 9RJ, UK.

(Email: wojtek.wojcik@kcl.ac.uk) young infant as a mechanism for permanently adjusting or 'programming' aspects of its physiology in response to the intrauterine and post-natal environment. This may provide adaptive fitness: exposure to poor nutrition in early life may programme glucose-insulin metabolism to maximise fitness by increased insulin resistance. The survival advantage gained in better handling early malnutrition may come at the cost of increased susceptibility to chronic disease in later life (Barker, 1995; Heijmans et al. 2008). However, the evidence is not universally supportive-a metaanalysis of $>50$ studies assessing the impact of low birth weight on hypertension concluded that previously reported effects were likely to be attributable to random error, reporting biases, inappropriate control of confounders and a weakening of the effect reported by studies over time (Huxley et al. 2002). The authors suggested that the evidence for other associations between low birth weight and adult health

The online version of this article is published within an Open Access environment subject to the conditions of the Creative Commons Attribution-NonCommercial-ShareAlike licence <http://creativecommons.org/licenses/by-nc-sa/2.5/ $>$. The written permission of Cambridge University Press must be obtained for commercial re-use. 
(e.g. depression) should be submitted to similarly critical scrutiny.

Population-based cohort studies have presented mixed results and there is currently no consensus whether low birth weight is associated with depression in later life (Thompson et al. 2001; Gale \& Martyn, 2004; Osler et al. 2005; Inskip et al. 2008). High-risk populations, including those exposed to famine, provide particularly strong evidence of an association. For example, Brown et al. (2000) found that men and women exposed to the Dutch Hunger Winter of 1944-45 during their second or third trimesters were at significantly increased risk of affective disorder [odds ratio (OR) 1.54, 95\% confidence intervals (CI) 1.12-2.13] for exposure in the second trimester). However, the interpretation of this finding is complex and difficult to generalise to less extreme conditions. Famine no doubt represents a complex cluster of exposures, which in the perinatal period could include extreme material deprivation, maternal ill health and severe stress. There is a need to consolidate the epidemiological data from population studies under more normal circumstances.

We conducted a systematic review of the published literature to determine whether there was evidence to support an association between low birth weight, defined as $<2500 \mathrm{~g}$, and depression or psychological distress in later life.

\section{Method}

\section{Inclusion of studies}

A literature search was carried using the PsycINFO (1967-2011), EMBASE (1980-2011) and Medline (19502011) databases and the Cochrane Library (final searches completed on 12 April 2011). The search string used was [Birth weight] AND [depression OR depressive disorder OR affective disorder OR psychological distress]. On completion of the literature search, a citation search was carried out using all the included records.

Inclusion criteria were that: (i) the study reported primary research; (ii) birth weight was the exposure variable; (iii) depression, depressive symptoms or psychological distress were the outcomes and were measured in the participant using self-rating scales or diagnostic interviews. This included anxiety and depression subscales of broader psychopathology questionnaires. We included the broader category of 'psychological distress' in recognition that some measures (for example, the Malaise Inventory ; Rutter, 1970) are designed to capture symptoms of anxiety and depression together and therefore overlap considerably with more specific depression scales or diagnostic interviews. We conducted a sensitivity analysis to determine whether inclusion of this broader category impacted on our results.

We included both cohort and case-control studies. Studies of clinical cohorts of premature or low weight births compared to normal weight births were included. We excluded other cohorts at 'high risk' for the exposure, such as studies on specific risk subgroups (e.g. malnourished mothers, famine). We also excluded studies that used health register data to identify outcomes.

\section{Data extraction}

Records were screened for inclusion by title and abstract. The full text shortlisted records were independently assessed for eligibility by two investigators (W.W. and W.L.). Where more than one study reported analyses from the same sample, the study that (a) best fitted the inclusion criteria then $(b)$ included the largest sample size in analyses was selected and the other(s) excluded. We used a data extraction sheet to record key information such as study design, method used to record birth weight and the method used to ascertain depression. We assessed study quality on a number of criteria: whether the participation rate was reported; the participation rate; correction for gestational age; correction for other confounders and sample size. Any discrepancies were discussed and, if necessary, referred to the senior author (M.H.).

Researchers have taken differing approaches to presenting the relationship between birth weight and later outcomes. Some have assessed a binary outcome (below or above a certain level) whereas others have modelled the impact of birth weight expressed as a continuous variable. Whilst the latter approach has the advantage of greater statistical power if the underlying relationship is a linear one, it is unclear whether the effect of birth weight on later outcomes would indeed be linear across the observed range of weights. We therefore extracted binary variables for exposure and outcome. This allowed us to test the hypothesis that an identifiable low birth weight (commonly accepted as $\leqslant 2500 \mathrm{~g}$ ) could be associated with subsequent adult depression. For studies that used continuous variables in their published analyses, authors were contacted to ask for analyses using binary variables.

\section{Meta-analysis}

The principal analysis was on the binary exposure and binary outcome. A random effects meta-analysis was conducted to combine the estimates from the studies. Random effects was preferred over fixed effects as we 


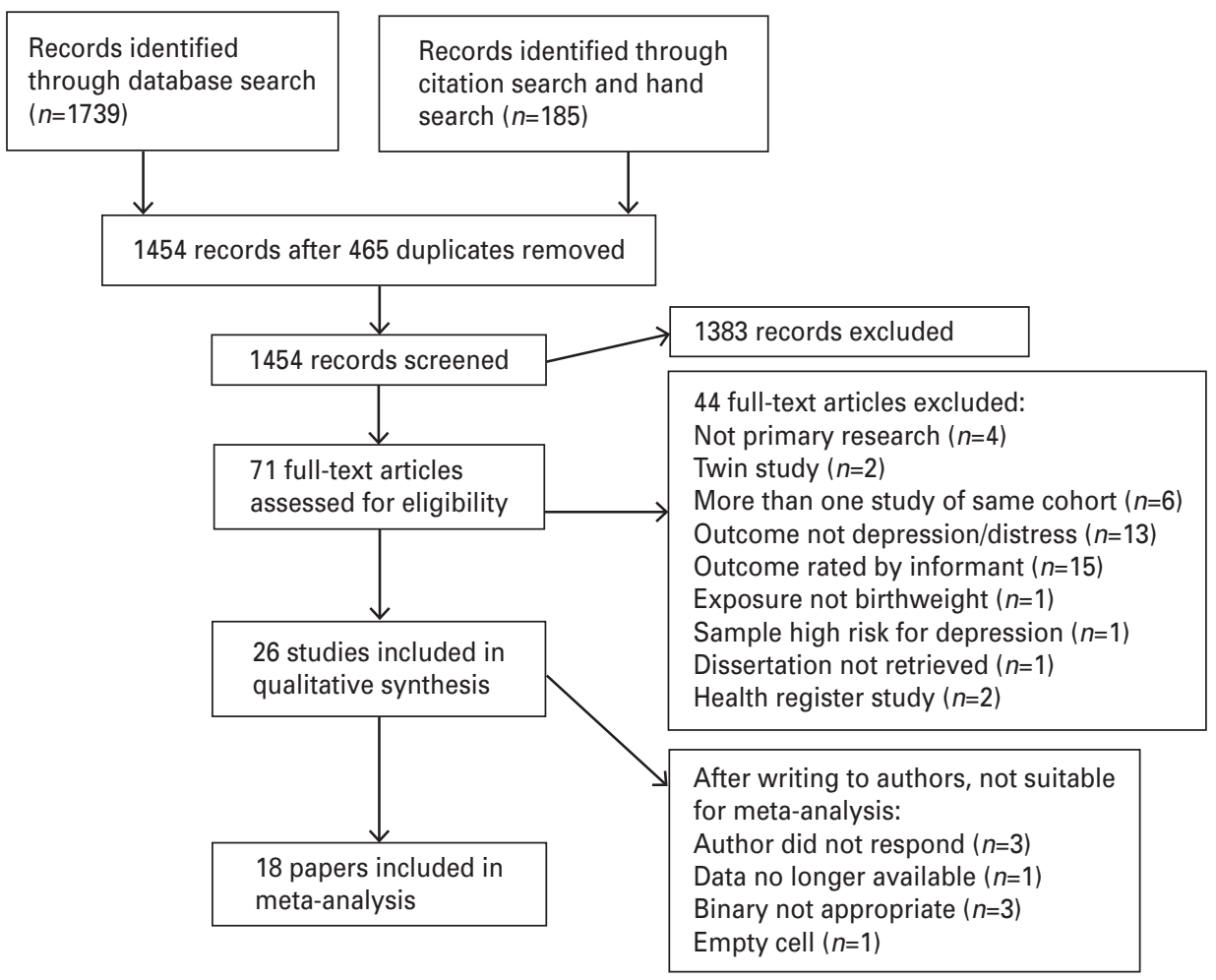

Fig. 1. Inclusion of studies.

expected moderate heterogeneity in effect sizes; however, we report estimates using both methods. Adjusted log odds ratios were used where available and where unavailable raw summary data were used to calculate the unadjusted log odds ratio. Studies were categorised by whether estimates were crude or adjusted for possible confounders and, if they were, whether they adjusted for gestation. We calculated the $I^{2}$ statistic to estimate the extent of heterogeneity. All analyses were carried out using Stata 10 (StataCorp, USA).

A funnel plot and a trim-and fill technique were used to assess and adjust for publication bias (Egger et al. 1997; Duval \& Tweedie, 2000). Hypothesised sources of heterogeneity were explored using metaregression. These were: (i) the degree of adjustment of study estimates (i.e. unadjusted; adjusted for variables not including gestation; adjusted for variables including gestation); (ii) the outcome measure (depression; psychological distress); (iii) sampling strategy (representative; selective); (iv) the proportion of women in the sample of each study. Studies were categorised by sampling strategy according to whether this was representative of the local population or selective, for example, by gender or low birth weight. Population-based cohorts, case-control studies nested within these and unselected hospital-based cohorts were classed as 'representative'. Split-cohort designs (comparing very low birth weight babies with healthy weight babies), single gender studies and other approaches were classed as 'selective'.

\section{Results}

\section{Description of eligible studies}

The search strategy returned 1739 records. Altogether, 26 met all criteria after two stages of screening (see Fig. 1 and Table 1 for study details). Of the 26 studies, 11 supported the hypothesis that low birth weight is associated with later depression and 15 did not find a statistically significant association. Of the 15 null studies, 13 reported positive findings for subgroups or other measures in the abstract. The mean age of participants within each study ranged from 11 to 85 years. Two studies used a sample restricted by gender (women only) (Inskip et al. 2008) (Gudmundsson et al. 2011). Nineteen studies reported on samples in Europe, five in North America and two in Australia.

Table 1 lists outcome measures used in the included studies, categorised by depression or psychological distress. Eleven studies reported measures of psychological distress as the outcome. These measures included combined anxiety and depression score on the Hospital Anxiety and Depression Scale (HADS; Berle et al. 2006), and other scales such as the 
Table 1. Summary of included summaries

\begin{tabular}{|c|c|c|c|c|c|c|}
\hline Study & $\begin{array}{l}\text { Design, population } \\
\text { and country }\end{array}$ & $\begin{array}{l}\text { Sample } \\
\text { size }\end{array}$ & $\begin{array}{l}\text { Exposure } \\
\text { (birth record } \\
\text { unless stated) }\end{array}$ & $\begin{array}{l}\text { Outcome measure, } \\
\text { depression/ } \\
\text { distress, age }\end{array}$ & $\begin{array}{l}\text { Result OR }(95 \% \mathrm{CI}) \\
\text { exposure: outcome }\end{array}$ & Comments \\
\hline Alati et al. 2006 & $\begin{array}{l}\text { Birth Cohort } \\
\text { recruited from } \\
\text { hospital; Australia }\end{array}$ & 3493 & 140 LBW (4\%) & $\begin{array}{l}\text { CES-D } \geqslant 16(\text { Dep }) \text { at } \\
21 \text { years; } 891 \text { cases } \\
(24 \%)\end{array}$ & $\begin{array}{l}1.55(1.03-2.35) \\
<2.5 \mathrm{~kg} v .>3.5 \mathrm{~kg}: \\
\text { depression }\end{array}$ & Adj OR (incl. gest) \\
\hline Batstra et al. 2006 & $\begin{array}{l}\text { Birth Cohort from } \\
\text { hospital; } \\
\text { Netherlands }\end{array}$ & 258 & $\begin{array}{l}\text { Mean weight (S.D.) } \\
=3143 \mathrm{~g}(698)\end{array}$ & $\begin{array}{l}\text { CIDI depression } \\
\text { (Dep) at } 20-25 \\
\text { years; } 32 \text { cases } \\
(12 \%)\end{array}$ & $\begin{array}{l}1.455(0.55-3.82) \\
\text { LBW: depression. }\end{array}$ & $\begin{array}{l}\text { Crude estimate } \\
\text { From author }\end{array}$ \\
\hline Bellingham-Young 2003 & $\begin{array}{l}\text { Cross-sectional } \\
\text { study; UK } \\
\text { students }\end{array}$ & 100 & $\begin{array}{l}4 \text { LBW }(4 \%) \text { by self- } \\
\text { report }\end{array}$ & $\begin{array}{l}\text { HADS depression } \\
\text { caseness (Dep) at } \\
\text { 19-62 years; } \\
21(21 \%) \text { cases }\end{array}$ & $\begin{array}{l}p=0.01 \text { for }<2.5 \mathrm{~kg} \\
v .3 .27-4.88 \mathrm{~kg}: \\
\text { depression }\end{array}$ & Not in meta-analysis \\
\hline Berle et al. 2006 & $\begin{array}{l}\text { Population cohort } \\
\text { (HUNT); Norway }\end{array}$ & 7806 & $271 \mathrm{LBW}(3 \%)$ & $\begin{array}{l}\text { HADS caseness } \geqslant 8 \\
\text { on anxiety or } \\
\text { depression } \\
\text { subscale (Dis), at } \\
20-30 \text { years; } 1184 \\
\text { cases }(15 \%)\end{array}$ & $\begin{array}{l}1.00(0.68-1.34) \\
\text { LBW: psychological } \\
\text { distress }\end{array}$ & Adj OR (incl. gest \\
\hline Cheung et al. 2002 & $\begin{array}{l}\text { Birth Cohort; UK } \\
1958 \text { birth cohort }\end{array}$ & 9731 & $\begin{array}{l}\text { Birth weight } \\
\text { continuous } \\
\text { measure }\end{array}$ & $\begin{array}{l}\text { Malaise Inventory } \\
\text { psychological } \\
\text { subscale 'high } \\
\text { distress' at } 23 \\
\text { years, } 33 \text { and } 42 \\
\text { years; 6-22\% } \\
\text { prevalence (Dis) }\end{array}$ & $\begin{array}{l}0.90(0.85-0.95) \\
\text { z-score birth } \\
\text { weight: } \\
\text { psychological } \\
\text { distress (OR <1 } \\
\text { supports } \\
\text { hypothesis) }\end{array}$ & Not in meta-analysis \\
\hline Colman et al. 2007 & $\begin{array}{l}\text { Birth Cohort; UK } \\
1946 \text { birth cohort }\end{array}$ & 3282 (at 36 years) & $\begin{array}{l}\text { At age } 36,99 \mathrm{LBW} \\
(3 \% \text { of } 3282)\end{array}$ & $\begin{array}{l}\text { Short form PSE } \\
\text { caseness at age } 36 \\
\text { (Dis) at } 36 \text { years; } \\
203 \text { cases }(6 \%)\end{array}$ & $\begin{array}{l}0.63(0.17-1.70) \\
\text { LBW : psychological } \\
\text { distress }\end{array}$ & $\begin{array}{l}\text { Crude estimate } \\
\text { From author }\end{array}$ \\
\hline Elgen et al. 2002 & $\begin{array}{l}\text { Non-population- } \\
\text { based cohort } \\
\text { study; Norway }\end{array}$ & 261 & $\begin{array}{l}130<2000 \mathrm{~g} \text { birth } \\
\text { weight }(50 \%) ; 131 \\
\text { controls }>3000 \mathrm{~g} \\
\text { birth weight }\end{array}$ & $\begin{array}{l}\text { CAS diagnosis of } \\
\text { depression (Dep) } \\
\text { at } 11 \text { years; } 3 \text { cases } \\
(1 \%)\end{array}$ & $1.8(0.2-21)$ & Adj OR (not gest) \\
\hline
\end{tabular}


Birth Cohort;

Northern Finland

1966 birth cohort

Fan \& Eaton, 2001

Frost et al. 1999

Gale \& Martyn, 2004

Godmundsson et al. 201

Hack et al. 2004

Haavind et al. 2007

Herva et al. 2008

Inskip et al. 2008
Prospective

population cohort

of women, with

birth records;

Sweden

Cohort; Johns

Hopkins

Perinatal Study

and Pathways

Study; USA

Prospective cohort

study without

northeast USA

1970 Birth Cohort

8292

Cohort of VLBW

babies and normal

weight controls

USA

Population cohort

(Young-HUNT);

Norway

Birth Cohort;

Finland 1966 Birth

Cohort

\section{Cross-sectional}

study;

Southampton

Women's Survey;

UK

1758

715

473

8519
Birth weight

continuous

measure

LBW $(15 \%)$

386 (191 women)

LBW by maternal

report (\% not

given)

465 LBW (6\%)

$3500 \mathrm{~g}(\%$ not

given)

7020 women

Recorded $(7 \%)$ or recalled $(10 \%)$

by recall for

controls

803 small for

gestational age

$<10$ th centile)

225 LBW (3\%)
SCL-25

psychological

at 31 years

GHQ-28 depression

subscale score $\geqslant 5$

(Dep) at 27-33

years

CDI depression scale $(\geqslant 12)($ Dep) at age $18 ; 61$ cases $(16 \%)$

Malaise Inventory $\geqslant 8$ (Dep) at 26 years; 1574 cases

(19\%)

DSMIII Lifetime

Depression, $44.6 \%$

240 VLBW; weight

ASR above 95th

centile for anxiety/

depression (Dis) at

20 years; 34 cases

HSCL-5 > 2, (Dis)

$581+228=$ at 13

19 years

HSCL-25 score

$\geqslant 1.75$ (Dep) at 31

years; 1206 cases

(14\%)

GHQ-12 score $\geqslant 3$

(Dis) at 20-34

years; 2497 cases

(32\%)
NS for birth weight

and psychological

distress

Not in meta-analysis

1.65 (0.58-4.67)

LBW: depression

Adj OR (not gest)

Women: $\beta=0.153$, $p<0.05$

Men: N.s., estimate

not given

LBW: depression

1.10 (0.84-1.43)

$<2.5$ vears

$>3.5 \mathrm{~kg}$ :

depression

$1.63(1.20-2.22)$

$<3500 \mathrm{~g} \mathrm{v}$.

$>3500 \mathrm{~g}$ : lifetime

depression

0.94 (0.46-1.94)

VLBW $v$. control:

distress

0.89 (0.68-1.14)

LBW : psychological

distress

$1.03(0.71,1.50)$

LBW: depression

1.13 (0.94-1.37)

LBW: psychological distress
Not in meta-analysis

Adj OR (incl. gest)

Not in meta-analysis

Crude estimate

Adj OR (incl. gest)

Crude estimate

Crude estimate

From author 
Table 1. (cont.)

\begin{tabular}{|c|c|c|c|c|c|c|}
\hline Study & $\begin{array}{l}\text { Design, population } \\
\text { and country }\end{array}$ & $\begin{array}{l}\text { Sample } \\
\text { size }\end{array}$ & $\begin{array}{l}\text { Exposure } \\
\text { (birth record } \\
\text { unless stated) }\end{array}$ & $\begin{array}{l}\text { Outcome measure, } \\
\text { depression/ } \\
\text { distress, age }\end{array}$ & $\begin{array}{l}\text { Result OR }(95 \% \mathrm{CI}) \\
\text { exposure: outcome }\end{array}$ & Comments \\
\hline Lahti et al. 2008 & $\begin{array}{l}\text { Birth Cohort; } \\
\text { hospital births } \\
\text { 1933-34; Norway }\end{array}$ & 1369 & $\begin{array}{l}\text { LBW; mean weight } \\
\text { (s.D.): } 3.4 \mathrm{~kg}(0.43) \\
\text { men, } 3.5 \mathrm{~kg}(0.48) \\
\text { women }\end{array}$ & $\begin{array}{l}\text { Harm Avoidance on } \\
\text { Cloninger's } \\
\text { psychobiological } \\
\text { model of } \\
\text { temperament (Dis) }\end{array}$ & $\begin{array}{c}\beta=3.3(0.9-5.7) \\
p=0.007 \\
\text { LBW }: \text { distress }\end{array}$ & Not in meta-analysis \\
\hline Mallen et al. 2008 & $\begin{array}{l}\text { Cross-sectional } \\
\text { study with birth } \\
\text { records UK }\end{array}$ & 521 & 31 LBW (6\%) & $\begin{array}{l}\text { HADS depression } \\
\text { score } \geqslant 8,(\text { Dep) at } \\
18-25 \text { years; } 78 \\
\text { cases }(15 \%)\end{array}$ & $\begin{array}{l}2.88 \text { (1.26-6.59) } \\
\text { LBW: depression }\end{array}$ & Adj OR (not gest) \\
\hline Patton et al. 2004 & $\begin{array}{l}\text { Nested case-control } \\
\text { study; Australia }\end{array}$ & 175 & $\begin{array}{l}\text { LBW 3\% (parental } \\
\text { report) }\end{array}$ & $\begin{array}{l}\text { CIDI diagnosis } \\
\text { (Dep) at mean } 16 \\
\text { years; } 63 \text { cases }\end{array}$ & $\begin{array}{l}2.9(0.6-14) \\
\text { LBW: depression }\end{array}$ & $\begin{array}{l}\text { Crude estimate } \\
\text { From author }\end{array}$ \\
\hline \multirow[t]{2}{*}{ Preti et al. 2000} & $\begin{array}{l}\text { Case-control ; Cases } \\
\text { from psychiatric } \\
\text { inpatient units }\end{array}$ & 82 & 6 LBW (7\%) & $\begin{array}{l}\text { Hospital diagnosis } \\
\text { of anxiety disorder } \\
\text { or depression (Dis) }\end{array}$ & $\begin{array}{l}\text { Empty cell in } \\
\text { supplied summary } \\
\text { data }\end{array}$ & Not in meta-analysis \\
\hline & 1988-97; Italy & & & $\begin{array}{l}\text { at } 18-28 \text { years; } 41 \\
\text { cases }\end{array}$ & $\begin{array}{c}\chi^{2}=1.03, \mathrm{df}=1 \\
p=0.31\end{array}$ & From author \\
\hline Raikonnen et al. 2007 & $\begin{array}{l}\text { Cohort; sample of } \\
\text { births in a Helsinki } \\
\text { hospital 1934-44 } \\
\text { Finland }\end{array}$ & 1371 & $\begin{array}{l}\text { LBW; birth weight } \\
\mathrm{kg}(\text { (s.D.) : } 3.5(0.5) \\
\text { men, } 3.4(0.4) \\
\text { women }\end{array}$ & $\begin{array}{l}\text { BDI score } \geqslant 10 \\
\text { (Dep) at average } \\
\text { age } 62 \text { years; } 256 \\
\text { cases }(19 \%)\end{array}$ & $\begin{array}{l}2.29(1.13-4.64) \\
\text { LBW: depression }\end{array}$ & $\begin{array}{l}\text { Adj OR (incl. gest) } \\
\text { From author }\end{array}$ \\
\hline Raikonnen et al. 2008 & $\begin{array}{l}\text { Cohort of VLBW } \\
\text { babies in neonatal } \\
\text { ICUs and controls; } \\
\text { Finland }\end{array}$ & 334 & 162 VLBW & $\begin{array}{l}\text { CES-D } \geqslant 16 \text { (Dep) at } \\
18-27 \text { years }\end{array}$ & $\begin{array}{l}0.62(0.36-1.07) \\
\text { VLBW v. control: } \\
\text { Dep }\end{array}$ & $\begin{array}{l}\text { Adj OR } \\
\text { From author }\end{array}$ \\
\hline Saigal et al. 2003 & $\begin{array}{l}\text { Cohort: regional } \\
\text { cohort of ELBW } \\
\text { children and } \\
\text { controls; Canada }\end{array}$ & 263 & $\begin{array}{l}141 \text { ELBW; weight } \\
\text { by recall for } \\
\text { controls }\end{array}$ & $\begin{array}{l}\text { OCHS-R } \\
\text { Depression } \\
\text { subscale score self- } \\
\text { report (Dis) at 12- } \\
16 \text { years }\end{array}$ & $\begin{array}{l}\text { NS for ELBW } v \text {. } \\
\text { control: distress }\end{array}$ & Not in meta-analysis \\
\hline Thompson et al. 2001 & $\begin{array}{l}\text { Regional birth } \\
\text { cohort born 1920- } \\
\text { 30; UK }\end{array}$ & 867 & $\begin{array}{l}152 \text { birth weight } \\
<3.0 \mathrm{~kg}(18 \%)\end{array}$ & $\begin{array}{c}\text { GMS } \geqslant 3 \text { or GDS } \\
\geqslant 5 \text { at } 68 \text { years } \\
\text { (Dep) } ; 74 \text { cases }\end{array}$ & $\begin{array}{l}1.49(0.62-3.57) \text { birth } \\
\text { weight }<3 \mathrm{~kg} \text { : } \\
\text { depression }\end{array}$ & Adj OR (not gest) \\
\hline
\end{tabular}




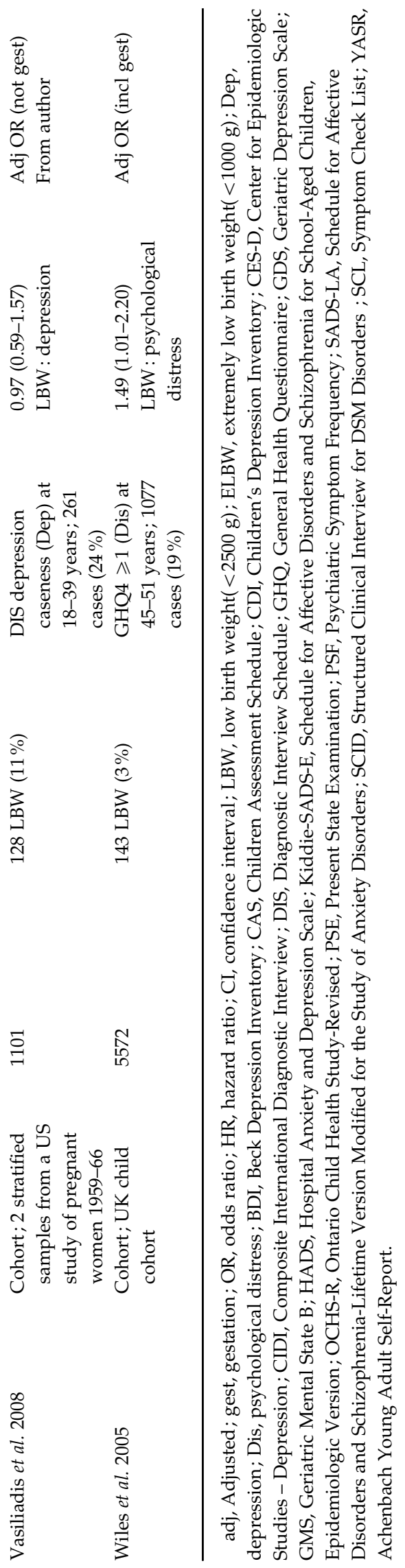

Achenbach Young Adult Self-Report (Hack et al. 2004) or the Hopkins Symptom Checklist (Haavind et al. 2007).

Fifteen studies reported measures of depression as an outcome. Depression scales included screening tools such as the HADS (Mallen et al. 2008) and Center for Epidemiologic Studies - Depression (Alati et al. 2007). One scale, the Malaise Inventory, was used as a measure of psychological distress by one study (Cheung et al. 2002) and as caseness for depression by another (Gale \& Martyn, 2004).

Twenty-two studies had a cohort design and 14 utilised non-selective sampling strategies and contemporaneous birth records to obtain birth weight. These included prospective studies that took all births from an entire population or a hospital and followed the sample to adult life and a retrospective cohort study that used birth records (Mallen et al. 2008).

Four cohort studies were of a split-cohort design, whereby cohorts of exposed and non-exposed individuals were compared (Elgen et al. 2002; Saigal et al. 2003, 2007; Hack et al. 2004; Raikkonen et al. 2008). Two studies were cross-sectional with self-reported birth weights (Bellingham-Young \& AdamsonMacedo, 2003; Inskip et al. 2008). Two case-control studies were also included, of which one was nested in a cohort study (Patton et al. 2004) and one was not (Preti et al. 2000).

The overall quality of studies was variable. The sample size for $28 \%$ of the studies was $<500$. Of the 18 studies included in the meta-analysis, $6 \%$ failed to report a participation rate. The remainder reported participation rates varying from $24-95 \%$ with a median of $72 \%$ and four studies reporting participation rates of $<50 \%$. This was calculated as the proportion of the population who could participate and did so fully (in some instances, these figures will have included deaths and other losses to follow-up). Nonparticipation may lead to the under-ascertainment of individuals with depression, as has been demonstrated in a study of non-participants (Knudsen et al. 2010). Altogether, $67 \%$ failed to control for gestational age and only $28 \%$ considered other confounders, with a wide range of confounders considered. No study simultaneously controlled for gestational age, maternal socio-economic status, maternal smoking, family history of depression and gender, all of which could plausibly confound the association between low birth weight and depression.

\section{Association between low birth weight and depression}

Estimates derived from appropriate binary measures of birth weight and depression were available for 18 


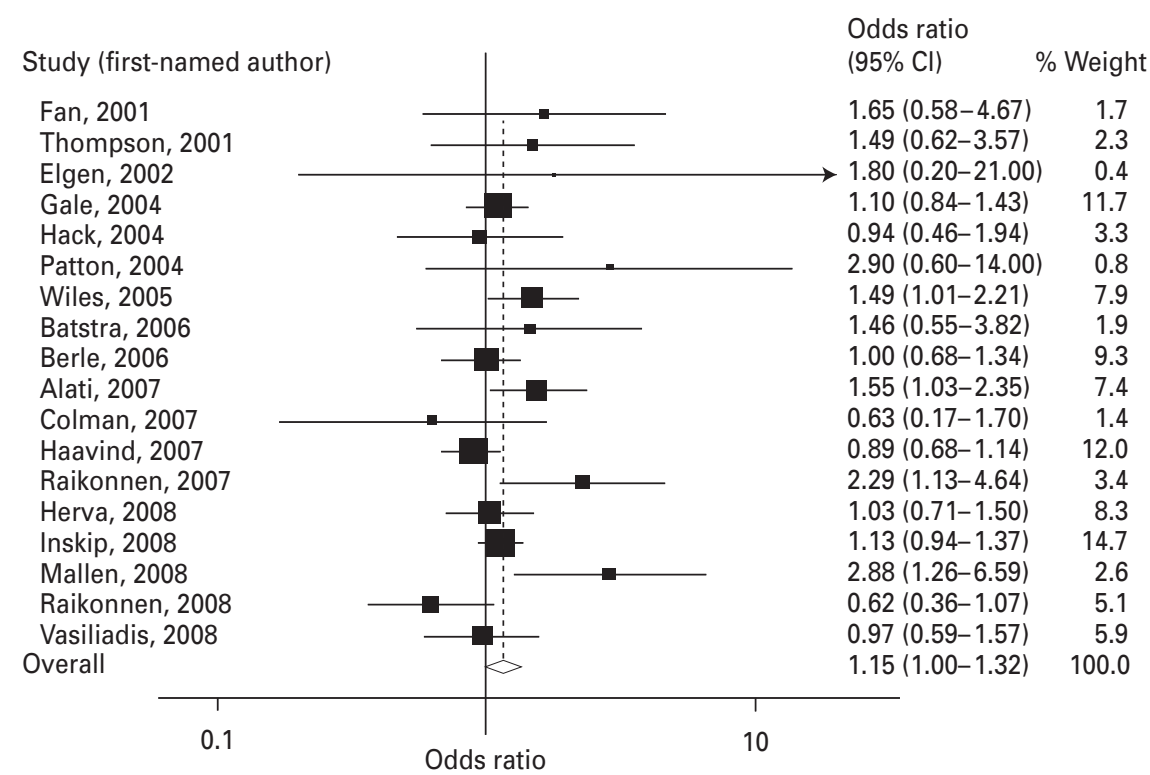

LBW: Less depression/distress LBW: More depression/distress

Fig. 2. Meta-analysis of 18 included studies. LBW, Low birth weight.

of the 26 studies (Fig. 2), including nine for which authors supplied the required information by correspondence ( 16 were contacted).

The random effects estimate for all 18 studies was OR 1.15 (95\% CI 1.00-1.32), with moderate heterogeneity $\left(I^{2}=34.5 \%, 95 \%\right.$ CI $<0.1-62.9, \chi^{2}=25.96$, $\mathrm{df}=17, p=0.075)$. The fixed effects model gave the slightly smaller OR and CI of 1.12 (1.01-1.23).

A funnel plot (Fig. 3) provided evidence of publication bias and the trim-and-fill technique was used to impute small missing null or negative studies. This imputed four missing studies, which resulted in a non-significant association at the 5\% level (OR 1.08, 95\% CI 0.92-1.27). The fixed effects model using trim and fill gave a similar effect size (OR 1.08, 95\% CI $0.98-1.19)$. The results were similar if the analysis was restricted to studies with the outcome of case-level depression only (not shown).

\section{Investigation of heterogeneity using meta-regression}

Studies were compared on two quality measures, the degree of adjustment for confounding and, second, the representativeness of the study samples. The six studies (Hack et al. 2004; Patton et al. 2004; Batstra et al. 2006; Colman et al. 2007; Herva et al. 2008; Inskip et al. 2008), which published crude estimates, were compared to the six studies (Fan \& Eaton, 2001; Thompson et al. 2001; Elgen et al. 2002; Mallen et al. 2008; Raikkonen et al. 2008; Vasiliadis et al. 2008), which corrected for variables not including gestation, a quality measure. The ratio of their estimates from meta-regression was 1.05 (95\% CI $0.62-1.77)$, compatible with no difference. Similarly, when the six studies' crude estimates were compared to those from the seven studies (Gale and Martyn, 2004; Wiles et al. 2005; Berle et al. 2006; Alati et al. 2007; Haavind et al. 2007; Raikkonen et al. 2007), which corrected for variables including gestation, no significant difference was found (OR 1.10, 95\% CI 0.72-1.68). Likewise, studies using more representative samples were similar to those using selective methods (OR 1.29, 95\% CI $0.90-1.87)$.

Additional potential sources of heterogeneity investigated were the outcome used and the gender mix of the samples. Studies where psychological distress was the outcome were found to have similar findings to studies where depression was the outcome (OR 1.18, $95 \%$ CI 0.85-1.64). Finally, the proportion of women in the sample of each study (fitted as a continuous variable) was not associated with variation in the association between low birth weight and depression (OR $0.82,95 \%$ CI $0.29-2.33$ ). The ratio describes the predicted relationship of estimates from notional allfemale and all-male studies in the meta-analysis.

\section{Studies not included in the meta-analysis}

Of the eight papers excluded from the meta-analysis, two reported analyses did not show a significant association, while five did and one reported an association for women but not men.

\section{Discussion}

In our meta-analysis of 18 studies, we have demonstrated a weak association between low birth weight 


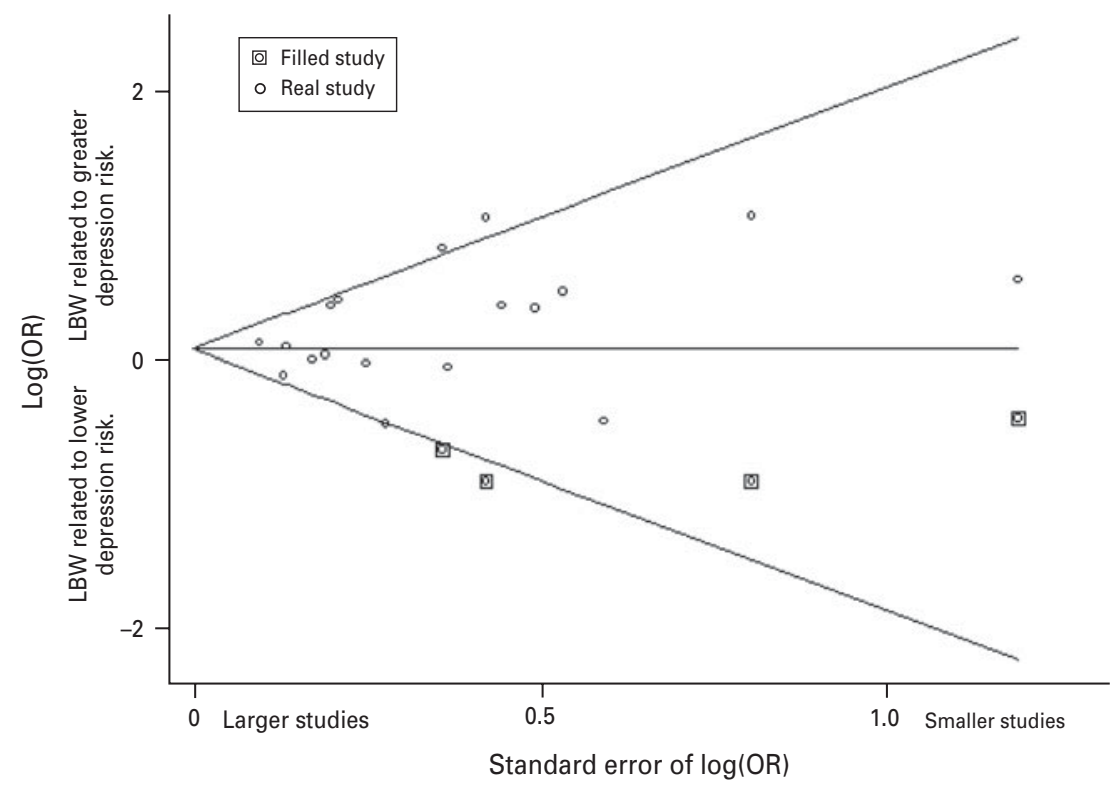

Fig. 3. Funnel plot, with imputed (' filled') missing small negative studies shown boxed. LBW, Low birth weight; OR, odds ratio.

and later depression, including psychological distress, which became non-significant after correction for probable publication bias. The same was true if the analysis was restricted to studies examining depression only. The interpretation of our findings depends on whether correction for publication bias is seen as appropriate. We think that publication and reporting biases are present for two reasons. First, the funnel plot (Fig. 3) suggested a small number of missing small null studies, which would be expected if publication bias is operating. Second, of the 13 studies that reported null findings in relation to our predetermined definitions of low birth weight and depression outcomes, the majority $(n=11)$ emphasised 'positive' findings in their abstracts, such as subgroup analyses or secondary exposures. Only two of these null studies did not prioritise other positive findings (Inskip et al. 2008; Vasiliadis et al. 2008). This suggests a preference for authors and journals to report positive findings while null findings are often downplayed, a phenomenon widely recognised (Fanelli, 2010). When we corrected for publication bias by using 'trim-and-fill' techniques, the effect became statistically non-significant and the effect size reduced. Steichen (2000) notes that the trim-and-fill procedure makes numerous assumptions and it therefore requires careful interpretation rather than being seen as an infallible correction, particularly given the fact that there was some heterogeneity between studies. Nonetheless, we think there is evidence of reporting and publication bias and that our metaanalysis should be interpreted as indicating no compelling association between low birth weight and adult depression or psychological distress in the populations studied.

There was, however, heterogeneity in the studies reviewed, with a wide age range of participants, outcomes used and populations. There may therefore be subgroups where the association between low birth weight and depression is stronger than that seen overall. Our exploration of modifier variables using meta-regression did not find that any explained a significant amount of the heterogeneity in the association. These included quality indicators such as the degree to which possible confounders were controlled for, the outcome measures used and how much the design resembled a population-based study, and other factors such as the proportion of women in the sample. However, in an exploration of heterogeneity one is dependent upon the quality of the reporting in the source studies and some variables that might plausibly contribute to heterogeneity (e.g. family history of depression, smoking, maternal physical health) were not routinely reported.

Another potential source of heterogeneity could have been that some studies included extremely low birth weight or very low birth weight infants recruited from specialist hospital environments and compared these to controls of normal birth weight. These study samples would have comprised markedly premature births compared to term births. This contrasts with population studies where the low birth weight infants would have been less severely underweight and premature. It would be expected that such studies would be more likely to show an association of low birth weight on depression, because of confounding 
by the challenge of being born developmentally immature and therefore more likely to suffer health difficulties (Irving et al. 2000; Walther et al. 2000). In fact, of three such studies, none supported the hypothesis.

Two studies did not record birth weight from contemporaneous records, relying on self- or parentreport for the majority of recruited subjects. The use of self-report measures of birth weight may lead to recall bias, particularly if the study hypothesis was known to participants. Inskip et al. in their survey of 7020 British women reported satisfactory agreement $(r=0.87)$ for the 1729 women for whom birth weights by both recall and record were available. Thus, if this approach has led to such bias, it is likely to have had only a minor impact on a minority of studies.

Outcome measures and outcome severity may have contributed to the heterogeneity of results, although we did not find this in our meta-regression of the variables described above. The pooled estimate remained statistically non-significant following adjustment for publication bias for both depression and psychological distress outcomes. However, depression is a relapsing and remitting illness and most studies simply report the association between low birth weight and a single 'snapshot' of depression ascertained at one point in adult life. It is of note that Colman et al. by identifying patterns of depression (and other psychiatric disorders) over the life-course found that those with the worst trajectories (of recurrent affective symptoms) had the lowest birth weight (Colman et al. 2007). Thus, the ascertainment of depression in many of these studies may not have been sufficiently sensitive to identify a subtle underlying effect. Psychological distress, a broad category used in research to capture a range of symptoms of anxiety and depression was included in this review. Sensitivity analyses indicated that including this broader term had no impact on the observed effect.

We excluded health register studies from our review because depression is largely undiagnosed in the general population and only a minority of severe and complex cases present to secondary mental health care (Goldberg \& Huxley, 1992). Three health register studies were, however, identified in our search strategy. One, by Osler et al., followed men born in Copenhagen in 1953 using a hospital discharge diagnosis of depression and found no association with low birth weight. Larsen et al. (2010) used Danish birth records linked with hospitalisations for affective disorder (including bipolar illness) and found a modest effect (OR 1.15, 95\% CI 1.01-1.31). Abel et al. (2010) reported a cohort study that combined Danish and Swedish births, resulting in a sample of 1.49 million, followed to their late $20 \mathrm{~s}$ for a diagnosis of affective disorders (including bipolar disorder). The study found modest, statistically significant effects (OR 1.37, 95\% CI 1.13-1.66). These studies of case registers provide mixed results, but Abel's paper suggests that low birth weight has a modest effect when the outcome is defined as severe affective disorders leading to contact with secondary care services.

\section{Strengths and limitations}

Strengths of this review included the first, to our knowledge, use of the meta-analytic method to evaluate evidence for this hypothesis and broad search strategy to allow for what is a very heterogeneous field. The studies we included had sufficient power to detect a small effect. The heterogeneity of study designs is a limitation, although we were able to investigate differences between studies using metaregression. Despite variations in study design, these did not seem to impact on the overall effect, although this technique may have limited statistical power.

We opted for a binary approach to the categorisation of birth weight using a recognised cut-point for low birth weight $<2500 \mathrm{~g}$. The main reason for so doing was that a continuous approach would have assumed each decrement of birth weight represented an equal increment in the odds of later disorder. Considering the large number of non-pathological constitutional influences on birth weight, especially within the normal ranges, we decided this would have been inappropriate.

As in any meta-analysis, our results are dependent on the quality of the underlying studies, which were variable. Many studies had low statistical power and poor or inadequately reported follow-up rates. Further, many did not control for confounding and it is possible that there may be other confounders that have been neither considered nor controlled for. The estimate was adjusted for gestation in only $39 \%$ of studies. As with all meta-analyses, publication and reporting biases are an important problem. We detected probable publication bias with an underreporting of small null or negative studies. We suggest that authors or journals might prefer not to publish small null studies when it was obvious that the study was underpowered. We also suggest that an absolute publication bias may be operating, whereby the probability of publication is influenced by a study's finding irrespective of sample size. This may be expected in observational work where large studies using secondary datasets may be carried out cheaply.

We therefore conclude that although there is a small statistically significant impact of low birth weight on adult depression this requires careful interpretation. We suggest that for mild to moderate unipolar 
depression detected in general population samples, publication bias is a sufficient explanation for this effect and that the conservative interpretation (i.e. that low birth weight is not associated with adult depression) is the most reasonable conclusion. However, there is evidence from one very large case register study that affective disorders (including bipolar disorder) of sufficient severity to lead to contact with psychiatric services are associated with low birth weight. A less conservative interpretation would be to ignore the possible impact of publication bias and report a small and probably clinically insignificant effect that may be accounted for by uncorrected (and possibly unknown) confounders. We conclude that there is insufficient evidence to support the hypothesis that low birth weight is associated with adult depression.

\section{Acknowledgements}

We thank the many authors of the original papers who answered our enquiries. W.W. is supported by the NIHR (National Institute of Health Research) Academic Clinical Fellowship Award. W.L. is supported by the UK Medical Research Council. I.C. is supported by a Population Health Investigator Award from the Alberta Heritage Foundation for Medical Research and a New Investigator Award from the Canadian Institutes of Health Research. R.H. is supported by the UK Medical Research Council. M.H. is supported by the NIHR Biomedical Research Centre for Mental Health at the South London and Maudsley NHS Foundation Trust and Institute of Psychiatry, King's College London and is a NIHR Senior Investigator.

\section{Declaration of Interest}

None.

\section{References}

Abel KM, Wicks S, Susser ES, Dalman C, Pedersen MG, Mortensen PB, Webb RT (2010). Birth weight, schizophrenia, and adult mental disorder: is risk confined to the smallest babies? Archives of General Psychiatry 67, 923-930.

Alati R, Lawlor DA, Mamun AA, Williams GM, Najman JM, O'Callaghan M, Bor W (2007). Is there a fetal origin of depression? Evidence from the Mater University Study of Pregnancy and its outcomes. American Journal of Epidemiology 165, 575-582.

Barker DJ (1995). Fetal origins of coronary heart disease. British Medical Journal 311, 171-174.

Barker DJ (2004). The developmental origins of adult disease. Journal of the American College of Nutrition 23, 588S-595S.
Barker DJ (2007). The origins of the developmental origins theory. Journal of Internal Medicine 261, 412-417.

Barker DJ, Bagby SP, Hanson MA (2006). Mechanisms of disease: in utero programming in the pathogenesis of hypertension. Nature Clinical Practice Nephrology 2, 700-707.

Barker DJ, Winter PD, Osmond C, Margetts B, Simmonds SJ (1989). Weight in infancy and death from ischaemic heart disease. Lancet 2, 577-580.

Batstra L, Neeleman J, Elsinga C, Hadders-Algra M (2006). Psychiatric morbidity is related to a chain of prenatal and perinatal adversities. Early Human Development 82, 721-729.

Bellingham-Young DA, Adamson-Macedo EN (2003). Foetal origins theory: links with adult depression and general self-efficacy. Neuroendocrinology Letters 24, 412-416.

Berle JO, Mykletun A, Daltveit AK, Rasmussen S, Dahl AA (2006). Outcomes in adulthood for children with foetal growth retardation. A linkage study from the NordTrondelag Health Study (HUNT) and the Medical Birth Registry of Norway. Acta Psychiatrica Scandinavica 113, 501-509.

Breslau N, Chilcoat HD (2000). Psychiatric sequelae of low birth weight at 11 years of age. Biological Psychiatry 47, 1005-1011.

Brown AS, van Os J, Driessens C, Hoek HW, Susser ES (2000). Further evidence of relation between prenatal famine and major affective disorder. American Journal of Psychiatry 157, 190-195.

Cheung YB, Khoo KS, Karlberg J, Machin D (2002). Association between psychological symptoms in adults and growth in early life: longitudinal follow up study. British Medical Journal 325, 749.

Colman I, Ploubidis GB, Wadsworth MEJ, Jones PB, Croudace TJ (2007). A longitudinal typology of symptoms of depression and anxiety over the life course. Biological Psychiatry 62, 1265-1271.

Duval S, Tweedie R (2000). Trim and fill: a simple funnelplot-based method of testing and adjusting for publication bias in meta-analysis. Biometrics 56, 455-463.

Egger M, Davey Smith G, Schneider M, Minder C (1997). Bias in meta-analysis detected by a simple, graphical test. British Medical Journal 315, 629-634.

Elgen I, Sommerfelt K, Markestad T (2002). Population based, controlled study of behavioural problems and psychiatric disorders in low birthweight children at 11 years of age. Archives of Disease in Childhood. Fetal and Neonatal Edition 87, F128-F132.

Fan AP, Eaton WW (2001). Longitudinal study assessing the joint effects of socio-economic status and birth risks on adult emotional and nervous conditions. British Journal of Psychiatry 40, s78-s83.

Fanelli D (2010). Do pressures to publish increase scientists' bias? An empirical support from US States Data. PLoS One 5, e10271.

Gale CR, Martyn CN (2004). Birth weight and later risk of depression in a national birth cohort. British Journal of Psychiatry 184, 28-33.

Goldberg D, Huxley P (1992). Common Mental Disorders. A Biosocial Model. Routledge: London. 
Gudmundsson P, Andersson S, Gustafson D, Waern M, Ostling S, Hallstrom T, Palsson S, Skoog I, Hulthen L (2011). Depression in Swedish women: relationship to factors at birth. European Journal of Epidemiology 26, $55-60$.

Haavind S, Bergin I, Brubakk AM (2007). Mental health, school and leisure time of adolescents born 'small for gestational age'. Tidsskrift for Den Norske Laegeforening 127, 1933-1937.

Hack M, Youngstrom EA, Cartar L, Schluchter M, Gerry Taylor H, Flannery D, Klein N, Borawski E (2004). Behavioral outcomes and evidence of psychopathology among very low birth weight infants at age 20 years.

Pediatrics 114, 932-940.

Heijmans BT, Tobi EW, Stein AD, Putter H, Blauw GJ, Susser ES, Slagboom PE, Lumey LH (2008). Persistent epigenetic differences associated with prenatal exposure to famine in humans. Proceedings of the National Academy of Sciences of the United States of America USA 105, 17046-17049.

Herva A, Pouta A, Hakko H, Laksy K, Joukamaa M, Veijola J (2008). Birth measures and depression at age 31 years: The Northern Finland 1966 Birth Cohort Study. Psychiatry Research 160, 263-270.

Huxley R, Neil A, Collins R (2002). Unravelling the fetal origins hypothesis: is there really an inverse association between birthweight and subsequent blood pressure? Lancet 360, 659-665.

Huxley R, Owen CG, Whincup PH, Cook DG, RichEdwards J, Smith GD, Collins R (2007). Is birth weight a risk factor for ischemic heart disease in later life? American Journal of Clinical Nutrition 85, 1244-1250.

Inskip HM, Dunn N, Godfrey KM, Cooper C, Kendrick T (2008). Is birth weight associated with risk of depressive symptoms in young women? Evidence from the Southampton Women's Survey. American Journal of Epidemiology 167, 164-168.

Irving RJ, Belton NR, Elton RA, Walker BR (2000). Adult cardiovascular risk factors in premature babies. Lancet 355, 2135-2136.

Jones PB, Rantakallio P, Hartikainen AL, Isohanni M, Sipila P (1998). Schizophrenia as a long-term outcome of pregnancy, delivery, and perinatal complications: a 28-year follow-up of the 1966 north Finland general population birth cohort. American Journal of Psychiatry 155, 355-364.

Knudsen AK, Hotopf M, Skogen JC, Overland S, Mykletun A (2010). The health status of nonparticipants in a population-based health study: the Hordaland Health Study. American Journal of Epidemiology 172, 1306-1314.

Larsen JK, Bendsen BB, Foldager L, Munk-Jorgensen P (2010). Prematurity and low birth weight as risk factors for the development of affective disorder, especially depression and schizophrenia: a register study. Acta Neuropsychiatrica 22, 284-291.

Mallen C, Mottram S, Thomas E (2008). Birth factors and common mental health problems in young adults: a population-based study in North Staffordshire. Social Psychiatry \& Psychiatric Epidemiology 43, 325-330.

Osler M, Nordentoft M, Andersen AM (2005). Birth dimensions and risk of depression in adulthood: cohort study of Danish men born in 1953. British Journal of Psychiatry 186, 400-403.

Patton GC, Coffey C, Carlin JB, Olsson CA, Morley R (2004). Prematurity at birth and adolescent depressive disorder. British Journal of Psychiatry 184, 446-447.

Preti A, Cardascia L, Zen T, Pellizzari P, Marchetti M, Favarento G, Miotto P (2000). Obstetric complications in patients with depression-a population-based casecontrol study. Journal of Affective Disorders 61, 101-106.

Raikkonen K, Pesonen AK, Heinonen K, Kajantie E, Hovi P, Jarvenpaa AL, Eriksson JG, Andersson S (2008). Depression in young adults with very low birth weight: the Helsinki study of very low-birth-weight adults. Archives of General Psychiatry 65, 290-296.

Raikkonen K, Pesonen AK, Kajantie E, Heinonen K, Forsen T, Philips DI, Osmond C, Barker DJ, Eriksson JG (2007). Length of gestation and depressive symptoms at age 60 years. British Journal of Psychiatry 190, 469-474.

Rutter M (1970). Psycho-social disorders in childhood, and their outcome in adult life. Journal of the Royal College Physicians of London 4, 211-218.

Saigal S, Pinelli J, Hoult L, Kim MM, Boyle M (2003). Psychopathology and social competencies of adolescents who were extremely low birth weight. Pediatrics 111, 969-975.

Saigal S, Stoskopf B, Boyle M, Paneth N, Pinelli J, Streiner D, Goddeeris J (2007). Comparison of current health, functional limitations, and health care use of young adults who were born with extremely low birth weight and normal birth weight. Pediatrics 119, 562-573.

Steichen, TJ (2000). Nonparametric trim and fill analysis of publication bias in meta- analysis. Stata Technical Bulletin STB-57, 8-14.

Thompson C, Syddall H, Rodin I, Osmond C, Barker DJ (2001). Birth weight and the risk of depressive disorder in late life. British Journal of Psychiatry 179, 450-455.

Vasiliadis HM, Gilman SE, Buka SL (2008). Fetal growth restriction and the development of major depression. Acta Psychiatrica Scandinavica 117, 306-312.

Walther FJ, den Ouden AL, Verloove-Vanhorick SP (2000). Looking back in time: outcome of a national cohort of very preterm infants born in The Netherlands in 1983. Early Human Development 59, 175-191.

Whincup PH, Kaye SJ, Owen CG, Huxley R, Cook DG, Anazawa S (2008). Birth weight and risk of type 2 diabetes: a systematic review. Journal of the American Medical Association 300, 2886-2897.

Wiles NJ, Peters TJ, Leon DA, Lewis G (2005). Birth weight and psychological distress at age $45-51$ years: results from the Aberdeen Children of the 1950s cohort study. British Journal of Psychiatry 187, 21-28. 